\title{
Experimental Study on the Effect of Short Basalt Fiber on Properties of Lightweight Aggregate Concrete
}

\author{
Li-guang Xiao ${ }^{1, a}$, Ji-heng Li ${ }^{1, b}$, Qing-shun Liü ${ }^{1, c}$ \\ ${ }^{1}$ School of Material Science and Engineering, Jilin Jianzhu University, Changchun130118, China \\ axlg627@163.com , b857496489@qq.com, ‘qingshunliu@126.com
}

Keywords: Volcanic cinder lightweight aggregate concrete; fiber reinforced concrete; basalt-fi ber; frost resistance; toughness

Abstract. In this paper, the experimental study on the modification of lightweight aggregate concrete with different content of basalt fiber is carried out, and the results show that the: With the increase of amount of basalt fiber, lightweight aggregate concrete slump decreases; compressive strength increases gradually, when reaching a maximum and then decreased; the flexural strength is improved obviously, improves the ratio of flexural toughness is greatly improved. SEM photo shows that the interface of basalt fiber and cement paste is good, the porosity of concrete is decreased, and the frost resistance of concrete is significantly improved.

\section{Introduction}

Lightweight aggregate concrete has the characteristics of light weight, heat preservation, thermal insulation and fire resistance ${ }^{[1]}$. However, the lightweight aggregate concrete early segregation problems, improper maintenance caused by drying shrinkage or cracking etc..Basalt fiber has excellent mechanical properties, and it is a kind of environmental protection fiber material, which has been widely used ${ }^{[2-4]}$. The basalt fiber reinforced concrete can effectively enhance the strength and toughness of concrete, restrain shrinkage, reduce the generation of cracks, improve the frost resistance of concrete, and improve the durability of concrete.

\section{The Experimental Process}

Raw materials and their properties. Cement: Jilin honored cement limited company. Production tripod deer card P.O 42.5 R ordinary Portland cement; Fly ash: meeting the national standards of grade II; Super plasticizer: Polycarboxylate superplasticizer; Basalt fiber: Jilin Jiuxin basalt Industry Co. Ltd. production, the main technical performance are shown in Table 1; Lightweight aggregate : Huinan County, Jilin Province, the volcanic slag, the main performance parameters in Table 2;Water: tap water.

Table 1 Basalt fiber physical and mechanical properties

\begin{tabular}{c|c|c|c|c|c|c|c}
\hline $\begin{array}{c}\text { Length } \\
(\mathrm{mm})\end{array}$ & $\begin{array}{c}\text { Diameter } \\
(\mu \mathrm{m})\end{array}$ & $\begin{array}{c}\text { Density } \\
(\mathrm{g} / \mathrm{cm} 3)\end{array}$ & $\begin{array}{c}\text { Elasticity } \\
\text { modulus } \\
(\mathrm{Gpa})\end{array}$ & $\begin{array}{c}\text { Breaking } \\
\text { elongation } \\
(\%)\end{array}$ & $\begin{array}{c}\text { Temper } \\
\text { ature } \\
\left({ }^{\circ} \mathrm{C}\right)\end{array}$ & $\begin{array}{c}\text { Water } \\
\text { content } \\
(\%)\end{array}$ & $\begin{array}{c}\text { Tensile } \\
\text { strength } \\
(\mathrm{MPa})\end{array}$ \\
\hline $17-19$ & 13 & 2.61 & $78.2-94.1$ & 3.0 & $<650$ & $<4$ & $4150-4800$ \\
\hline
\end{tabular}

Table 2. The performance parameters of cinder

\begin{tabular}{c|c|c|c|c}
\hline $\begin{array}{c}\text { Particle Size } \\
(\mathrm{mm})\end{array}$ & $\begin{array}{c}\text { Bulk density } \\
(\mathrm{kg} / \mathrm{m} 3)\end{array}$ & $\begin{array}{c}\text { Cylinder pressure } \\
\text { strength }(\mathrm{MPa})\end{array}$ & $\begin{array}{c}\text { 1h Water absorption } \\
(\%)\end{array}$ & $\begin{array}{c}\text { Conductivity } \\
(\mathrm{W} / \mathrm{mk})\end{array}$ \\
\hline $0-8$ & 1.0 & 5.0 & 30.6 & 0.0802 \\
\hline
\end{tabular}

Specimen preparation and testing. The effects of different amount of basalt fiber on the properties of lightweight aggregate concrete are studied in this experiment. The 6 groups of 
different specimens were fabricated, and the basalt fiber content was $0,0.1 \%, 0.2 \%, 0.3 \%, 0.4 \%$, $0.5 \%$, respectively. The slump of lightweight aggregates of volcanic slag was first determined, The flexural strength and compressive strength of the specimens were tested after curing for 28 days under standard conditions, Part of the specimen into the freeze-thaw cycle equipment to reach the specified number of cycles measured under the mass loss rate and dynamic modulus. Micro analysis using TM3030 scanning electron microscope to observe the concrete section of the volcanic cinder lightweight aggregate concrete.

\section{Results and Discussion}

Effect of Basalt Fiber on the Slump of Lightweight Aggregate Concrete. The influence of different content of basalt fiber on the slump of lightweight aggregate concrete is shown in Fig.1.

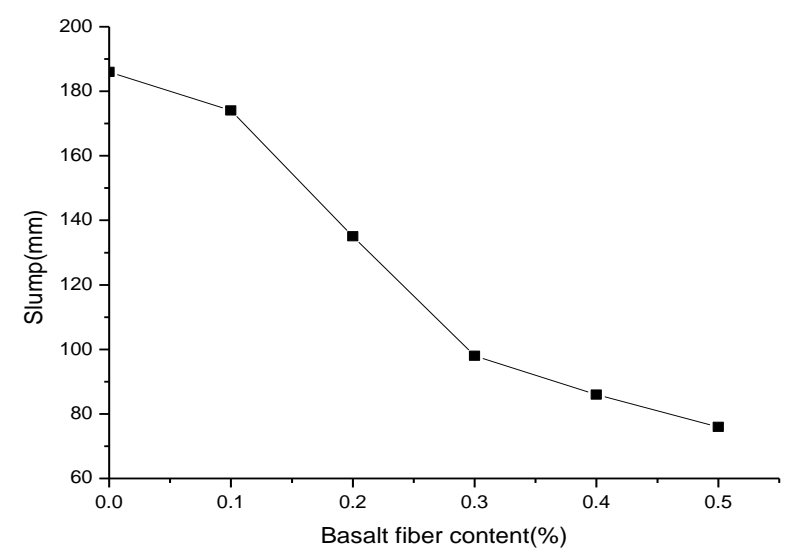

Fig.1 Effect of different content basalt fiber on slump of lightweight aggregate concrete of volcanic slag

From Fig.1, the incorporation of basalt fiber was decreased after volcano slag lightweight aggregate concrete slump, and with the increase of fiber volume, the concrete slump dropped significantly. This is because the basalt fiber itself is larger than the surface area, a part of the surface of the fiber is required for the inclusion of a slurry, While the amount of slurry used to coat the aggregate of the volcanic slag as well as the lubricating effect is correspondingly reduced. At the same time, fiber in concrete is a three-dimensional random distribution, the effect of slag lightweight volcano liquidity concrete aggregate, resulting in concrete slump loss.

The Influence of Basalt Fiber on Strength of Lightweight Aggregate Concrete. Basalt fiber's influence on cinder light aggregate concrete flexural strength and compressive strength is shown in fig.2 and fig.3.

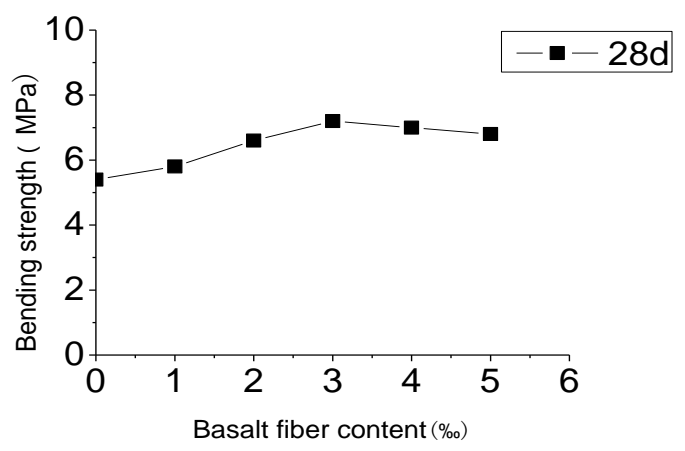

Fig.2 Basalt fiber on flexural strength of lightweight aggregate concrete

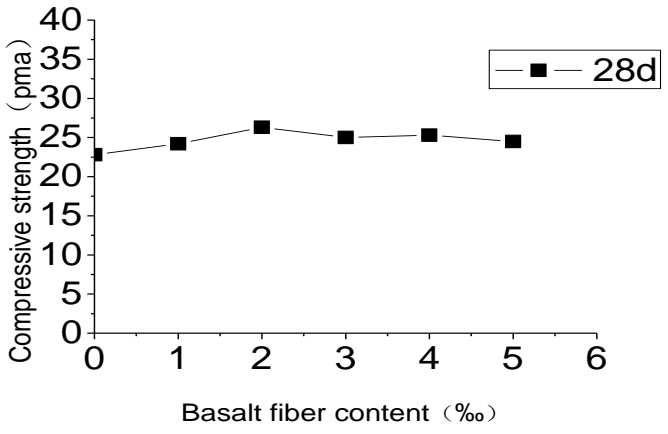

Fig.3 Basalt fiber on compressive strength of lightweight aggregate concrete

It can be seen from Fig. 2 and 3 that the compressive strength of light-weight aggregate concrete increases slowly with the increase of basalt fiber content, it decreases when the mass content of basalt fiber reaches $2 \%$, The basalt fiber content increases gradually, and the flexural strength of 
the lightweight aggregate concrete is also strengthened. When the basalt fiber content is $3 \%$, the flexural strength appears an optimal point.

\section{Effect of Basalt Fiber on Frost Resistance of Lightweight Aggregate Concrete}

The quality and dynamic elastic modulus of the groups of $\mathrm{B}_{0}, \mathrm{~B}_{1}, \mathrm{~B}_{2}, \mathrm{~B}_{3}$ four groups of test specimens were measured at each of the 25 times of freeze-thaw cycles. The related test data are shown in Table 3.

Table 3 The relationship between the relative dynamic elastic modulus and mass loss rate of the basalt and the lightweight aggregate concrete

\begin{tabular}{ccccccccc}
\hline $\begin{array}{c}\text { Times of freezing } \\
\text { and thawing cycles }\end{array}$ & \multicolumn{3}{c}{ Relative dynamic elastic modulus $(\%)$} & \multicolumn{5}{c}{ Mass loss rate $(\%)$} \\
\hline & $\mathrm{B}_{0}$ & $\mathrm{~B}_{1}$ & $\mathrm{~B}_{2}$ & $\mathrm{~B}_{3}$ & $\mathrm{~B}_{0}$ & $\mathrm{~B}_{1}$ & $\mathrm{~B}_{2}$ & $\mathrm{~B}_{3}$ \\
\hline 0 & 100 & 100 & 100 & 100 & 0 & 0 & 0 & 0 \\
25 & 90.2 & 95.6 & 96.0 & 97.4 & 0.1 & 0.1 & 0.1 & 0 \\
50 & 79.6 & 85.6 & 86.3 & 86.8 & 0.3 & 0.3 & 0.3 & 0.2 \\
75 & 64.5 & 75.5 & 81.2 & 81.5 & 0.5 & 0.4 & 0.4 & 0.5 \\
100 & 53.8 & 65.5 & 71.5 & 72.6 & 1.0 & 0.8 & 0.7 & 0.6 \\
125 & & 51.6 & 61.2 & 64.3 & & 1.3 & 1.2 & 1.0 \\
150 & & & 54.7 & 57.2 & & & & \\
\hline
\end{tabular}

From Table 3, the relative elastic modulus of the plain concrete $\mathrm{B}_{0}$ decreased to $53.8 \%$ after 100 freeze-thaw cycles, and the relative elastic modulus of all concrete specimens with basalt fibers was maintained above $60 \%$. When 125 times of freeze-thaw cycles, the relative dynamic elastic modulus of $\mathrm{B}_{1}$ decreased to $51.6 \%$, while the relative dynamic elastic modulus of $\mathrm{B}_{3}$ and $\mathrm{B}_{2}$ were still more than $60 \%$. After 100 freeze-thaw cycles, the mass loss rate of $\mathrm{B}_{0}$ was $1 \%$, and the mass loss rates of the three groups of basalt fibers were all less than $1 \%$. This shows that the fiber has a positive effect on the freezing and thawing damage of concrete, and it can effectively improve the frost resistance of lightweight aggregate concrete with basalt fiber as reinforcement.

\section{Mechanism analysis}

In order to further verify the basalt fiber is essentially the influence of compressive strength, how the volcano slag lightweight aggregate concrete flexural strength and frost resistance, using SEM scanning electron microscope on different dosage of basalt fiber volcano slag lightweight aggregate concrete specimens of micro fracture surface analysis, Mass ratio of $0.1 \%, 0.2 \%, 0.3 \%, 0.4 \%, 0.5 \%$ of the five components of different basalt fiber content of volcanic slag light aggregate concrete microstructure shown in Fig.4 - Fig.8.

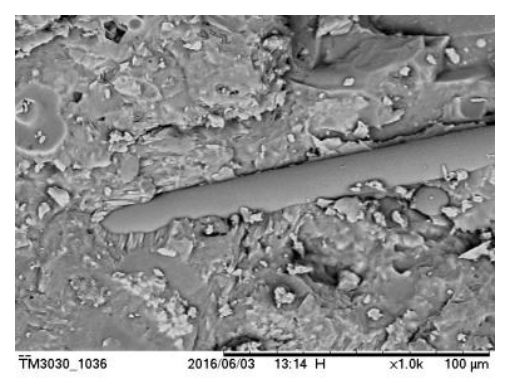

Fig.4. 0.1\% dosage of SEM

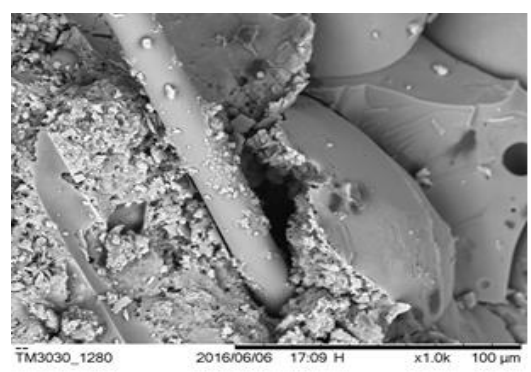

Fig.5. 0.2\% dosage of SEM

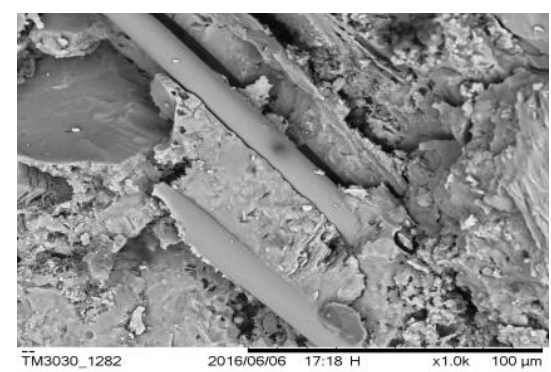

Fig.6. 0.3\% dosage of SEM 


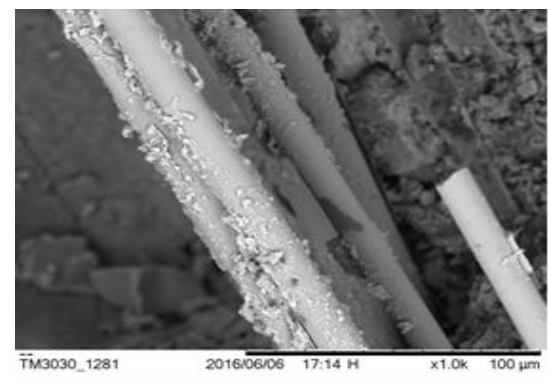

Fig.7. 0.4\% dosage of SEM

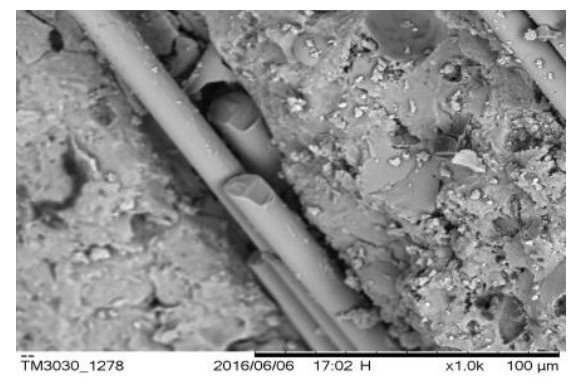

Fig.8. $0.5 \%$ dosage of SEM

Fig.4 shows basalt fiber content of $0.1 \%$ basalt fiber and volcanic slag lightweight aggregate concrete substrate bonding interface amplified 1000 times the SEM photos. Basalt fiber mixed with concrete, and the concrete matrix common load, fiber drawing and friction makes the concrete can absorb more energy, the cohesion between the various components of the material is strengthened. Therefore, the flexural strength than the plain concrete is much greater, the strength of concrete is enhanced.

Fig. 5 can be seen, basalt fiber content of $0.2 \%$, The fiber surface and the matrix have a good combination of morphology, basalt fiber well to prevent the expansion of the interface micro-cracks. To a certain extent continue to improve the basalt fiber lightweight aggregate concrete mechanical properties.

Fig.6 shows that $0.3 \%$ of the basalt fiber as reinforcing material has good dispersion and compactness in the concrete, and has a good degree of fusion with the matrix, and has no agglomeration phenomenon, and plays a supporting role in the concrete matrix. The results show that basalt fiber has a good dispersion effect in concrete with $0.3 \%$ basalt fiber content, and it is suitable for compacting even inside the concrete, and the reinforcing effect is the best.

Fig. 7 and Fig. 8 show the SEM images of the interface between fiber and matrix when the mass fraction of basalt fiber is $0.4 \%$ and $0.5 \%$ When the excess fiber is mixed into the concrete, there will be fiber overlap and the phenomenon of agglomeration, will inevitably lead to a large number of adhesive interface and the emergence of holes, increasing the weak link within the concrete, And these weak links in the process of concrete load is prone to fracture and become a source of cracks, resulting in a significant decline in mechanical properties.

\section{Conclusion}

(1) Basalt fiber volcano slag lightweight aggregate concrete, water retention and cohesiveness has been strengthened, but will lead to a decline in the slump.

(2) After the basalt fiber is mixed into the lightweight aggregate concrete, the flexural strength and plastic deformation capacity of the lightweight aggregate concrete are significantly improved.

(3) After the basalt fiber is mixed into the lightweight aggregate concrete, the flexural strength and plastic deformation capacity of the lightweight aggregate concrete are significantly improved.

\section{Acknowledgements}

This work was financially supported by the National Key Technologies Research and Development Program of China(No. 2016YFC0701002).

\section{Reference}

[1] Jia-yun Jing, Ming-Zao, Ya-bing liu, Lijun-Chen. Since the insulation block of coal cinder light aggregate concrete production process [J]. Journal of new building materials, 2014,p.10-14 .

[2] Zhu-lin Wang, basic mechanical properties of hybrid fiber reinforced high strength concrete research [J]. Journal of engineering and construction, 2015, p.660-662 . 
[3] Gao Lei, Guo-hui Hu, Xu Nan, Jun-yi Fu. Research progress on the engineering properties of basalt fiber [J]. Journal of underground space and engineering, 2014, p.749-1754 .

[4] Qiao- min He, Wei-guo hu. Basalt fiber concrete proportion and performance study [J]. Journal of highway and trucks, 2016, p.121-125 . 